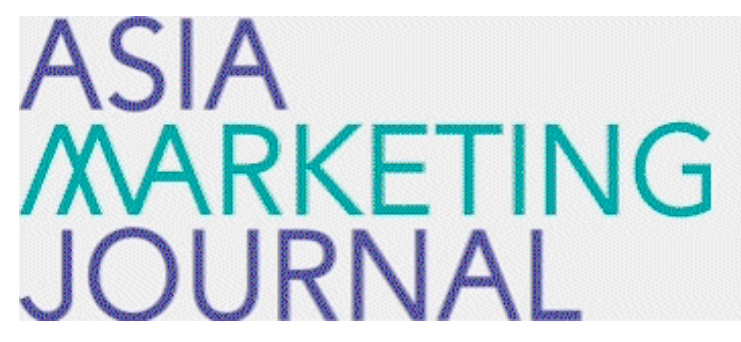

ASIA MARKETING JOURNAL

Volume 22 | Issue 4

Article 5

$1-31-2021$

\title{
Labour of Love: Fan Labour, BTS, and South Korean Soft Power
}

Jasmine Proctor

Follow this and additional works at: https://amj.kma.re.kr/journal

Part of the Marketing Commons

\section{Recommended Citation}

Proctor, Jasmine (2021) "Labour of Love: Fan Labour, BTS, and South Korean Soft Power," Asia Marketing Journal: Vol. 22 : Iss. 4 , Article 5.

Available at: https://doi.org/10.15830/amj.2020.22.4.79

This Article is brought to you for free and open access by Asia Marketing Journal. It has been accepted for inclusion in Asia Marketing Journal by an authorized editor of Asia Marketing Journal. 


\title{
Labour of Love: \\ Fan Labour, BTS, and South Korean Soft Power
}

\author{
Jasmine Proctor*
}

\begin{abstract}
With the steady rise in global popularity of the Korean music group BTS, the South Korean government and surrounding industries have swiftly begun utilizing their image and international recognition for specific nation branding purposes. While $\mathrm{K}$-pop soft power strategies are not novel to the South Korean state, what is new is the rapid speed at which BTS have become a beacon for South Korean culture, language, and symbolism in the international arena. However, few scholarly works have sought to investigate the role fans have played in this heightened position for the group as state representatives, with minimal research conducted into the work fans do within the framework of ARMY fan culture. This paper will thus aim to fill the gap in scholarship on ARMY as an organized labour network, focusing on the role fans play as labourers in online spaces that work to promote, disseminate, and cultivate wider recognition for BTS as artists. Through the conjunct engagement of a political economy framework and theories of participatory culture, this paper will explore the manner through which the free labour of ARMY, premised on affect, has constructed the fandom as active agents of soft power alongside BTS themselves.
\end{abstract}

Keywords: Fan labour, Hallyu, Soft Power, BTS, Cultural Diplomacy, South Korea

\section{Statement of Intended Contribution}

This paper sits at a unique junction point, where fan studies and the political economy of communication meet. While previous studies have employed the two perspectives to investigate how international fans have contributed to the processes of globalization or the sociopolitical potential of fan activism, scholarship has rarely endeavoured to understand the role transnational networks of fans play in the arena of soft power. Previous studies have analysed fan work as labour full stop, but little to no research has been conducted into how ARMY labour,

\footnotetext{
* Simon Fraser University (jasminemproctor@gmail.com)
} 
specifically, manifests and translates into nation branding potential. Specifically, no study has analyzed the various forms of labour that take place within the BTS fandom, ARMY, through ethnographic means in order to uncover how, implicitly and explicitly, these labour practices have contributed to the acquisition of soft power for the South Korean state. In this way, this paper aims to answer the question of how fan-led labour initiatives work to market not only BTS, but South Korea to a global audience in the pursuit of soft power by employing qualitative methods of interview and participant observation, uncovering that the dialectic of affect and duality of affinity that results in global expansion.

This study thus adds to our understanding of organized fan networks as digital publics and expands upon notions of fan-led marketing initiatives in the realm of value production. On a more general scale, this research is extremely relevant for government agencies who have previously relied on more top-down notions of cultural diplomacy, warranting a focus on the element of transnational and transcultural fandom in the soft power equation.

\section{Introduction}

On October 20th, 2020, Jimin of the South Korean group, BTS, hosted a 32-minute mediated chat with BTS' fan community, ARMY, through the streaming platform, Vlive. In the half an hour he was speaking, he addressed topics ranging from the COVID-19 pandemic, answered fans' questions, provided encouragement, but he also discussed his 25th birthday that has just passed. In this segment, Jimin pointed out and acknowledged the hard work fans had put into running events, trending hashtags, and celebrating Jimin across the globe. All of these events, while focused on Jimin in this case, are components of the ARMY fandom structure, ranging from hashtags to billboards to even cafe cupsleeve events held across the globe. While celebratory in nature, what these events represent and point to is a key notion prevalent within the fandom structure, namely the presence of fan work and the opportunities it affords for cross-cultural understanding and global representation. Specifically, this fan work represents a type of labour within the digital gift economy of fandom that translates into soft power for South Korea as a nation state through networked affinities premised on affect. Central to this paper's concept of ARMY fan labour as soft power is, ultimately, an understanding of how labour functions within the digital sphere. With the rise of Web 2.0, participation online has become synonymous with creative and information-based labour forms (Gill and Pratt, 2008; Fuchs, 2010), where the individual consumer is now, in the age of media convergence, has also become the producer 
(Jenkins 2008: Moisander, Könkkölä, and Laine 2013). As Terranova (2013) relays, online labour has become synonymous with free labour, precarity colouring the terrain upon which work is undertaken across the web and within the frameworks of online platforms. This idea is central to our understanding of fan labour, as the participatory nature of fan spaces online (Jenkins 2016), such as ARMY's occupation of Twitter, lends itself to the idea of free labour as both wageless and freely given (Terranova 2013). The digital environment is positioned within a culture of participation that is fertile terrain for creative labour practices to occur, and fandom is one of these junction points. Fan work can thus be understood as free labour (De Kosnik 2013), but the operations in which value is generated (Turk 2013) and the cycle of fan exchange complicate these more traditional understanding.

In this paper, I explore this exact junction point as it relates to the network of labour ARMY have built rooted in affect and fandom cultural practices. Through analyzing the various forms through which ARMY affinity manifests as labour, the work fans put in to not only creatively reinterpreting texts (Lamerichs 2018), but also constructing the fan community premised on accessibility, my aim is to elucidate how the value produced from these operations manifests in soft power. This constructs ARMY essential part of the soft power equation, but also showcases how the fandom wields this power themselves, deconstructing and subverting traditional political economy understandings of passive audiences (Duffe, 2013) and pathologized fan stereotypes (Jenson 1992: Sandvoss, Gray, and Harrington 2017). This paper thus adopts an ethnographic approach through in-depth interviews and participant observation, alongside a qualitative analysis of secondary source, in order to illustrate how the affective investment in both BTS as well as the transcultural fan community not only leads to a form of soft power being achieved, but is a direct result of a dialectic rooted in work as fan cultural practice.

\section{Fan Labour and the Cultivation of Value}

Free labour within fan communities is anything but a novel concept, as fandoms themselves are premised on work as a means of participation. Web 2.0 has allowed fan communities to move from the fringe to the mainstream, with access being achieved through online spaces and social media platforms. This spreadable nature of the Internet (Jenkins, Ford, and Green 2013) has afforded fans the means to participate in new ways, extrapolating the participatory culture (Jenkins 2006) of fan identities through engaging in the construction of fan texts (Lamerichs 2018; Oberc 2016). Web 2.0 has brought with 
it a blurring of the boundaries between producers and consumers (Bakioğlu 2018; Jenkins 1992; Bruns 2006), where fans' participation in the remediation of their texts, of the promotion and distribution of not only fan-created objects, but also of the main fannish texts themselves, can be understood as a form of free labour (Milner 2009; Baym and Burnett 2009; Bakioğlu 2018). As De Kosnik (2013) writes:

"fan activity, instead of being dismissed as insignificant and a waste of time at best and pathological at worst, should be valued as a new form of publicity and advertising, authored by volunteers, that corporations badly need in an era of market fragmentation. In other words, fan production is a category of work." (p.99).

As with any understanding of labour, constructing how value is generated and determined requires an understanding of how scholarship views fandom operations. Many have written on the gift economic functioning of fan communities (Hellekson 2009; Galuszka 2015; Bakioğlu 2018) and have noted the innate participatory nature of fandom in online spaces makes for a new interpretation of how we understand relationships to work (Milner 2009; Baym and Burnett 2009; Bakioğlu 2018). Hellekson (2009) defines this fandom economy as one based on exchange, both of ideas and of work, where the community is made up of giving, receiving, and reciprocation. The motivation for work is not monetary compensation, but solidifying a social structure and a connection to the fannish object, and "payment" for work manifests in the form of participation and engagement. Reciprocation exists through leaving "kudos" on a work of fan fiction, retweeting a piece of fanart, and sometimes even posting a photo of a birthday event cupsleeve to share on Twitter. Work is situated within the notion of gifts of the collective, where giving is not always one-to-one, but rather one-to-many (Turk 2014), as ideas, texts, and creations are meant to be disseminated as a part of the fandom culture.

Value operates differently within this structure, and while it does not function completely outside of the capitalist economy, it does warrant a reinterpretation of its role in discussions of exchange. Several scholars posit that fan activity adds value to media texts, resulting in a Marxist idea of surplus value and benefit to the industry (Stanfill 2019; Milner 2009; Helens-Hart 2014; Baym and Burnett 2009). Others, however, argue that this definition lacks the nuance required to understand how individuals within the collective fan structure view their relationship to the text, each other, and their own fan identities. Hills (2002) posits a "dialectic of value" that results from fan production and consumption, wherein objects are endowed with fannish meaning and take on a form of value based on this prescribed significance. In the same vein, Turk (2014) illustrates that while this can be understood as 
a labour theory of value, it is not within the Marxist sense of the concept, but rather in the simple idea that value is derived from work. Put plainly, there is value to fan work that exists within the fandom structure, but not necessarily in the economic sense. Both instances symbolize how fan communities perceive the value generated along the lines of meaning and affect. How we understand value in this capacity is crucial for understanding why fans participate, and how that lends itself to the forms of promotion and distribution they conduct.

\section{Soft Power and Cultural Diplomacy in South Korea}

Fan work, in this capacity, has the potential to market not only fannish objects, but even nation states through the notion of soft power and related acts of cultural diplomacy. Simply understood, cultural diplomacy represents a form of diplomacy that has its roots in the exchange of culture or ideas within the global sphere in pursuit of strengthened relations, mutual understanding, and to enhance a country's image (Kozymka 2014; Cummings 2003). The concept stems from understandings of public diplomacy, being a subset focused on utilizing cultural products for the purpose of diplomatic relations (Melissen and Cross 2013, as cited in Kim and Jin 2016), and becoming a crucial part of foreign policy as a distinct diplomatic resource (Kim and Jin 2016). Cultural diplomacy as a subset of public diplomacy are the actions put in place through policy to establish a country's brand. While these policies may result in soft power, they are not innate to it.

Instead, soft power can be understood as the ability to attract and persuade outside of the realm of coercion (Nye 2004). This type of power, according to Nye and Kim (2013) can be derived from 3 main resources: "1) the attractiveness of its culture, 2) its political values, when it lives up to them at home and abroad, and 3) its foreign policies, when they are seen as legitimate and having moral authority" (p.32). Soft power is thus a strategy enacted through cultural diplomacy, relating to a nation's ability to affect others through attraction rather than coercion, juxtaposing it with the notion of hard power, framed as the implementation of military and economic tools to coerce and influence. Nye (2004) views soft power as the act of getting others to want what you want through the exchange of ideas, a means through which nation branding can ultimately be achieved, as soft power resources "are assets that produce such attraction" (Nye 2008, p.95), often times finding itself in the form of popular culture products (Nye and Kim 2013).

Soft power as a goal has found itself embedded into much of South Korea's cultural diplomacy efforts and foreign policy over the last several 
decades, through direct support of the cultural industries. According to Kim and Jin (2016), since the 1960s, Korea has been focused on state-led developmental models and has enforced a top-down and export-led economy, having more recently implemented policies geared towards utilizing the popularity of South Korean cultural texts in the global sphere, otherwise known as the Korean wave. This wave, commonly known as Hallyu, has over the course of the past decade shifted from a regional phenomenon to a globalized movement (Oh and Lee 2014; Jin 2016). Transitioning from regional distribution of dramas and cinema, to transnational exportation of Korean popular music (K-pop) and gaming, Hallyu has seen a global spike in popularity (Jin and Yoon 2014). With its commercial success in global media markets, the Korean government has constructed cultural policies dedicated to supporting the creative industries (Oh and Lee 2013; Kim 2017), focused solely on the global exports of Korean cultural products into foreign markets.

Consequently, the growing global popularity of the industry has manifested in the mobilization of K-pop as a South Korean soft power instrument (Watson 2012). While previous national efforts have focused on the cultural industries as a key soft power strategy, Walsh (2014) states that the recent global success of $\mathrm{K}$-pop has revealed the potential for the domestic music industry to act as a national brand. Government policies have begun working towards the use of $\mathrm{K}$-pop as a means of establishing South Korea's global identity, painting a picture that is projected into the international sphere through their music industry. This has manifested itself through global $\mathrm{K}$-pop-themed events, such as annual $\mathrm{K}$-pop competitions across the world, hosted by South Korean embassies and consulates (Han 2017; Sung 2014), and global friendship concerts (Herman 2018a). South Korea's K-pop soft power continues to develop, as increasingly more artists promote in the global music sphere, through international tours, globally-accessible platforms for online content, and global media coverage of $\mathrm{K}$-pop begins to rise.

While $\mathrm{K}$-pop as a cultural form has become a soft power resource over the last decade, the expansive popularity of group BTS in the global sphere has quickly shifted much of the government's efforts towards harnessing their image as a soft power tool. Originating from a small company, with members' hometowns spread throughout the country, BTS represent a unique image of South Korea, with their own underdog story (Lee 2019) mirroring that of the country itself (Oh 2018). While it is hard to date the exact surge in BTS' global reach, as it can rather be viewed as a steady progression, there was a notable shift that occurred in 2017 following the group's win at the Billboard Music Awards for Top Social Artist (Lipshutz 2017). This year also marked their notable American Music Awards performance of title track DNA, which saw a rise in fan 
membership and global recognition due to the wide reach of broadcasting (Connellan 2017). 2017 is similarly of high importance when considering BTS as a soft power resource, as this also marks the year the group became Seoul City's Honorary Tourism Ambassador (Haddad 2019). Donning this title resulted in a wide sweep of tourism advertisements utilizing the band's image, such as the 'Live Seoul Like I Do' campaign, where the group takes the virtual fan on a tour of their favourite places in Seoul.

BTS as a group also represents not only images of South Korea in the global arena, but promoters of Korean culture through their performance on the international stage. Their music video for title track "Idol" off of their 2018 album, Love Yourself: Answer showcased the members in traditional hanbok, integrating these cultural images with a celebration of their transnational status through the music video's imagery and sound (Big Hit Labels 2018). More recently, the group took over The Tonight Show Starring Jimmy Fallon, performing tracks such as "Dynamite", "Home”, and "Black Swan". Two of these performances, "Idol" and "Mikrokosmos", showcased parts of Gyeongbokgung Palace in Seoul, with the group performing in hanbok for the former (Dodson 2020; Shetty 2020). Through these instances, BTS not only represented South Korea as a nation state, but promoted and showcased their culture through performance on mainstream U.S. television. The group's ability to celebrate and represent Korean culture has also resulted in recognition from the South Korean government, as well as the international community, with the group receiving both the South Korean Order of Cultural Merit (Herman 2018b) in 2018, as well as the Van Fleet Award in 2020 (Kang 2020). Evidently, the South Korean government is aware of the potential and power BTS themselves possess as a global movement and an entity for cross-cultural influence.

However, while BTS themselves possess unquestionable potential in the realm of soft power, there also needs to be an understanding of how ARMY play a role in this equation, and how, ultimately, the power ARMY as a fandom possesses within the arena of promotion and marketing signifies a direct link to soft power potential. What this points to is a need for reevaluation of traditional understandings of how soft power is achieved, as the notion of a top-down, state-led initiative does not fully fit within the framework of Web 2.0 digital practices and ARMY fan culture. How does fandom, in the sense of a transcultural fandom situated within a South Korean context, problematize the more top-down approaches to our understandings of soft power? How can the collective organization of fan work that ARMY enacts be translated into a crucial element within the nation branding structure? 


\section{Methodology}

To answer these questions, this paper focuses its analysis and data collection on the lived experiences of fan creators and how they understand the work that they do, its relationship to value, and its connection to wider global outreach. Therefore, this project employs qualitative methodology rooted in ethnography, under the idea that this approach "show[s] us the real movement of experience in the concrete world" (Willis 2014). To achieve these means, two key methods were employed: participant observation and in-person interviews with self-identifying fan creators. The first method in order to understand how fans promote BTS as fannish texts, specifically in the form of fan-run events, work to cultivate cross-cultural understanding, tourism, and lead to global expansion. It was also chosen due to my own positionality as an active member of the ARMY community and local fan worker, as well as familiarity with the structure of ARMY-run events. This participant observation was conducted over the course of 4 months, wherein I actively attended fan-led meet-ups where free merchandise was given away outside concert venues, as well as fan-run cafe events to celebrate member's birthdays and anniversaries. Additionally, observation was taken through my own enactment of fan labour as a group order manager, and use of secondary sources such as news reports and media texts were employed through an interpretive lens.

The second was utilized in order to shed light on how fan workers understood their position within the fandom structure and the reasons for participating in the ways that they do. Interviews were conducted throughout the months of November to January, both in-person in South Korea and Canada, as well as online. Recruitment was conducted across three of the major social media platforms utilized, Twitter, Tumblr, and Facebook. These platforms were chosen due to their overall activity rate amongst ARMY groups, and the intersections of various forms of fan work (i.e. spaces fan writers post links to their work, where fansites share photos, or group order managers operate). Overall, 21 out of the 24 participants identified as ARMY and active contributors to the fandom. The interviews were semi-grounded in structure, with general questions pertaining to work participants did, why they did it, and the average amount of time spent.

\section{Analysis and Findings}

Of the 21 interview participants, two identify as translators, nine are writers or editors, two publish YouTube videos, four do art, one collects, four run events, two host group orders, and two create music (see Figure 1). Five participants 
occupied multiple spaces of fan creation, and spoke to both experiences within the timeframe of the interview. There was also, notably, an interesting dialectic taking place between the type of work fans undertook, and the type of work mentioned within the interviews themselves. Many times fans referenced to other forms of work that they noticed within the fan community, or engaged with on the receiving end. This highlighted the same themes I, as a participant, have observed within the fan community, as one object of fan work was not mutually exclusive from the other portions of fan production. Group order work, such as I undertook, is also premised on the labour of fansites and fan artists, which constitute a network of labour that results in a double-engagement on the end of the receivers. Similarly, fanfiction festivals, as some interviewees brought up, also involve engagement with fan art, as writers and artists will team up on projects to contribute.

In this way, the ARMY fan structure is premised on labour that takes shape both online and off. This can be seen with the migration of fan work online migrating to the offline space, such as the advertising of fan goods being given away on Twitter manifesting in the physical space outside of concerts or at fan

〈Figure 1〉 Varying degrees of fan work in ARMY fandom

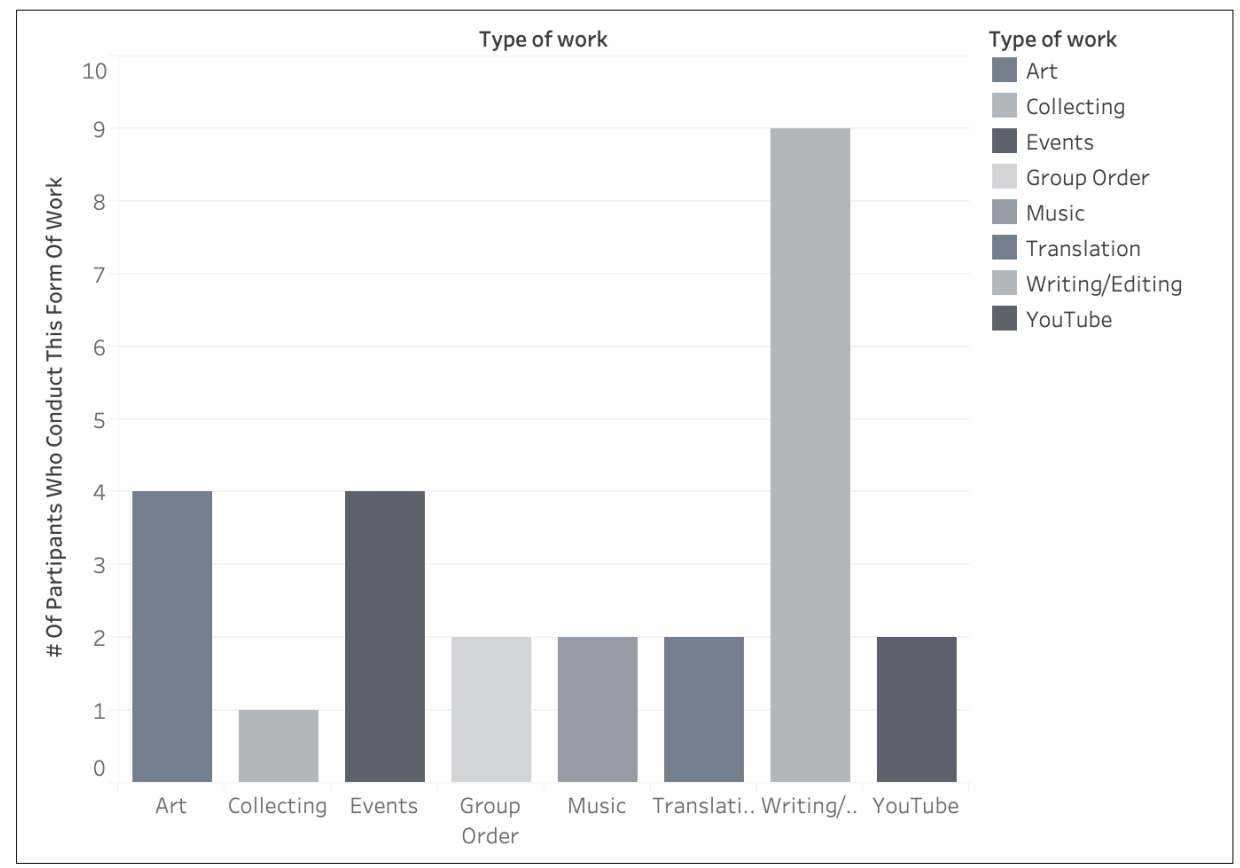

Note. This figure showcases the different types of ARMY fan work identified through this study, as well as the number of participants who identified as partaking in each specific type. 
events. The spatiality of the online realm that affords spreadability is not contained to social media platforms in the context of ARMY fan work, as the networked online spreads to the transnational, geographical world. In this way, the ARMY labour network of both immaterial and material, local and global. The affective nodes and ties that link ARMY across the globe are means through which the fandom spread awareness about BTS, their music, their message, and Korean culture to those within and outside the community. From streaming parties, comeback goal videos, fancams, donation and philanthropic work, to visual fanwork like fanfiction, art, and fansites, to even group order accounts that provide access to BTS' work - ARMY has established the avenues for accessibility that allow for not only a dissemination of the group's work and image into the global sphere, but also ultimately in new fandom member acquisition.

\subsection{Fan content and spreading awareness/accessibility}

The dissemination and representation of BTS through ARMY's online work has become a leading factor in new members finding media texts, and ultimately identifying with the fan community. Several interviewees recounted their own experiences of joining the fandom as being directly linked to fan creations, consuming fan content becoming a means through which they developed an affinity for BTS as artists. As one interviewee described, fanwork on YouTube was the main initial factor that led to their interest in the group, stating:

"I was on my laptop, just going through YouTube one day, and I got recommended a reaction video by this channel I was subscribed to and they happened to be reacting to the BTS cypher series and I was like oh that's odd, what's a cypher?... And so, you know, I started to look into BTS and then from there it was about late 2016 and I kind of just fell in and let it all consume me I guess."

While not always the first encounter with BTS-related content, others mentioned the relationship fan work had in the next steps towards becoming ARMY and developing a deeper connection with BTS. As Lee (2019) notes, "all fans 'enter the fandom' in their own unique ways, but ARMY wouldn't have become the vast international fandom of today if it weren't for YouTube-a bottomless treasure trove that houses hundreds of official videos by BTS and over thousands of times more fan-created content about BTS" (p.17). As one interviewee claimed, there is a common process through which new fans approach their fan identity in its initial stages, with a significant part being consumption of fan content such as YouTube in order to become oriented with the group and the fandom's dynamics, stating: 
"For instance, how many people do I know that they've seen, like, you know, those videos on YouTube? Those 'crack' videos on YouTube? Like how many people have, you know, fell down the rabbit hole with that one video, right? Yeah, I think that's how I fell down, too"

As expressed in both instances, the fan texts ARMY construct through their labour aids in the widely-held motif of "falling down the rabbit hole". The access afforded through fan creations like reaction or "crack" videos as mentioned lends itself directly to the idea of ARMY's gift economy. Several interviewees commented on their own work in this regard, stating that the idea of providing access to BTS' past was a key motivator for their own active participation. This complemented the sentiment held by many as to why they conduct the work they do, relaying their motivations through ideas of access, giving back, and maintaining the community. Gift exchange, as Hellekson (2009) explains, is how the economy of fandom operates; it is the value of participation and community maintenance that is premised on reciprocation. In the case of ARMY, this reciprocation offers a double-meaning, interpreted as both engagement with fan texts but likewise through providing access to new members. Work is conducted through this lens of entry and aid, but also functions to give back to the community in the same way many joined it.

\section{2 'Fan content and the dialectic of affect}

While accessibility represents a major portion of the motivations behind the fan labour conducted within the ARMY community, the affective connection between the fandom and its artist also plays an integral role. Fan work operates within the realm of creating ties to BTS, but also to the fandom as a community. Feeling connected to BTS leads to feeling connected to the fan community, as intimacy is cultivated through shared understanding and knowledge. As Stanfill (2019) describes, this idea of intimacy is crucial for the maintenance of fandom, as fandom is premised on affect. The existence of fan work and participation in the fan community connects the individual fan to the transcultural and transnational collective. This, within the context of ARMY, results in a dialectic of intimacy with fandom and intimacy with BTS. Content creation as an entry point into BTS is also simultaneously the entry point into the community, a sentiment echoed by the vast majority of interviewees. As one content creator reflected,

"I feel like.' we create bridges. We create ways that people can access the fandom and remain connected to the fandom. So that's what I do and other fanfic writers, we connect people a little bit more." 
Connection is a key concept here, especially when looking at the role creators play in the ARMY fan community. As Lamerichs (2018) regards, fandom can be understood as the presence of creativity and remediating texts, a poaching (Jenkins 1992) that connects fans through their related experiences with their fannish objects. In this way, fan creation becomes a central factor of the fan's relationship with BTS as artists because of its centrality to the community. Fandom experience with content or events that are fan-run can not only deepen the individual ARMY's connection to BTS, but also simultaneously solidify their identity within the greater fan community. Several interviewees reiterated this necessity of fan creation as the solidifying factor of intimacy, with one claiming

"They are the fan community. Fan creation is the definition of fan community. Yeah. And even people who don't create content, like fic, art, whatever, if you're on Twitter and you quote retweet something and you're like [laughs] congratulations, like you made content. Yeah, so I feel like that's what it is. Like'. you don't have that fandom if you don't have content creation."

With content creation and participatory work being the identifying factor of the fan community, the connection that ARMY have to one another is premised on a shared value through creation. This value situates itself around the idea of ARMY fandom being a "taste culture" (Thornton
1995), wherein operations function and ties are constructed through participation based around BTS as the common denominator (Lee 2019, p. xvii). This dialectic of affect, while originating at taste, translates into a need to give back or help the community through their combined efforts. Hellekson (2009) notes that one of the main motivators behind fandom participation is this notion of exchange, returning the value that was provided through original fan works back into the community for others to enjoy. Almost all ARMY interviewed mentioned similar ideas, explaining their reasoning for contributions along the lines of participation and "giving back" One interviewee discussed the desire to work and run events as an expression of love, stating

"Oh, my God. I just love ARMY so much. Like, I can't even put it into words, I'm gonna cry. But it's just like, they were constantly there for me, though, [so it's like] giving back and like making sure that they have an outlet."

Fandom spaces have historically been analyzed as subcultural communities defined by their connections to cultural objects, but also their presence as spaces of connection through shared values. As Morimoto and Chin (2017) write, transcultural fan spaces produce a form of camaraderie that transcends national borders and individual cultures. While not an absolute, this idea rings true in relation to ARMY fandom and their online and offline work, as individuals' 
affinity for their own ARMY community, constructed through labour, affords a connection to the wider transcultural network.

\subsection{Fan work as transcultural practice}

Through this dialectic of affect, ARMY fan work has the ability to spread fan culture and national cultural practices that ultimately lead to an affinity for Korean culture through BTS. While conducting field work in South Korea, one form of fan work observed was the culture of cupsleeve events. These are typically held at multiple cafes in celebration of a member's birthday, mixtape anniversary, or the group's debut date. At cupsleeve events, cafes are decorated with images, slogans, or significant memorabilia of a member or members, allowing fans to engage and take photographs. ARMY are able to purchase drinks or food, often memberthemed, and receive a designed cupsleeve along with their purchase. These cupsleeves are produced and designed by fans, many times by fansites (or hom-ma, 홈마) who use the photos they have taken of the member or members throughout the year and collaborate with the cafe to host the event. Many fans collect cupsleeves from a variety of events over the span of a weekend or days surrounding the anniversary being celebrated, keeping the added gifts of photocards or stickers that come with them as affective tokens of fanship.

While many events take place during the span of several days (or, sometimes, until the cupsleeves run out), ARMY are able to keep track of which is happening on what days and at which location through several ARMY-made and run webpages, including "ARMY Map". Available in English, Korean, and Chinese, ARMY Map was a crucial component of the fieldwork in South Korea as it showcased a variety of events occurring throughout Seoul during the months of my stay. The webpage offers fans up-to-date information about events occurring not only in Seoul, but also all throughout South Korea (Army Map 2019). While the map also showcases fan-made content such as billboards and subway advertisements available for viewing, the primary focus here was on how fan-run events such as cupsleeves operated as a means of cross-cultural understanding and transference of culture.

These practices of celebrating a member's birthday or mixtape anniversary, while originating in South Korea, have spread across the globe. Several of my interviewees, in fact, were cupsleeve event organizers outside of South Korea, who desired to translate this domestic fan practice into international fan cultural experiences. Through the global reach of fan events like the ones noted above, as well as awareness via platforms such as Twitter and ARMY map, a transcendence of fan cultural practice occurs, transferring the same norms and rituals over to non-Korean contexts. This transference results as a direct cause of access- 
rooted labour, as fans who have heard or experienced Korean fan-practices such as cafe events wish to create a means for fans overseas to experience them as well. As one interviewee mentioned:

"I just want people to enjoy [these events] because... no one has really done, like, the cupsleeve events [before]...Cause, like, you see a lot in Korea and I never went to Korea... So I really wanted [to host] one."

As with YouTube videos aiding in the initiation process of new ARMY, so too does the work of fans aid in fostering an understanding of Korean domestic fan culture. In this way, BTS' cultural background plays a significant role, as the process of becoming a fan and constructing a connection to the group and the fandom occurs through understanding the Korean culture. As one interviewee marked,

"It's just letting, like, new ARMY know, like, what's going on [in Korea]. Like a lot of new people, like, don't know how they debuted or like what they've been through. Like through culture, like Korean [fan] culture, too, they can get more exposed to how it's like there"

Through this, ARMY gain insight into the local practices of Korean fans and are able to develop an affinity for Korean culture within their own geographical context. This reflects back the intimacy that constructs ARMY connection with one another. As with the idea of fan work premised on accessibility to BTS and the ARMY fandom, fan-led events such as these also work to provide a connection across fan cultural practices, bridging the gap between domestic and international practices. Fan work aids in the creations of transcultural ARMY practices such as these, bridging the spatial gap of geography through a transference of culture. In this way, overseas cupsleeve events represent a means of accessing and understanding how the domestic fan culture operates, as one interviewee mentioned

"This is $\cdots$ like spreading Korean culture, to me. Because like in Korea this is a really big thing, like cupsleeve events. They hold it for like a week... a week and a half or like until they don't have any more cupsleeves. Like, for us, because we have, like, really limited [quantity] so we usually hold it for like one or two days. I think.... yeah, it just gives more fans more exposure to like Korean culture."

Cupsleeve events are not the only means through which ARMY fan labour is also producing an affinity for Korean culture, however. Twitter accounts such as @army_language and @BangtanAcademy_ have actively worked to provide ARMY's with the tools required to learn Korean, offering classes and tutorial sessions via Twitter and Discord (ARMY Language ${ }^{7}$ 2020; Bangtan Academy 2020). ARMY seeking to watch interviews or Vlives without subtitles have access through this work to learn BTS' 
native language, and this sparks an even further desire to connect with BTS' home culture. A love for BTS can lead to a curiosity about Korean culture, and the group can act as a gateway for an affinity for Korean culture and it's national image (Sung 2014). This has resulted, evidently, in an increase in tourism, with the Korean Foundation for International Cultural Exchange reporting that 7.6 percent of South Korea's international tourism per year has been directly linked to BTS' international appeal, with close to 800,000 tourists visiting the country for BTS-related purposes each year (Economic Effect of BTS' Conquest 2020). While K-pop themed tours and site visits have seen a boom following the rise of Hallyu 2.0 (Kim, Mayasari, and Oh 2013), very few of these are fan-led. Instead, ARMY have utilized their online network to construct their own BTS pilgrimages, showing international ARMY the various cafes, filming sets, locations, and other sites that are significant to BTS as artists through sites such as Twitter and Reddit (AmyOt7 2020). Labour performed in this capacity, through the sharing and constructing of fan tours, is dually an act of continuing the cycle of giving back latent in ARMY fandom, but also a means of creating another bridge between the international community and South Korea through this affinity.

An affinity for the fan community alongside BTS manifests in an understanding and appreciation for South Korea as a nation. This has extended beyond the realm of fan work, branching into the official content the group's company, BigHit Entertainment, has begun to produce. In 2020, the company launched their educational subsidiary, Big Hit Edu, in collaboration with Korean Language Contents Institute at the Hankuk University of Foreign Studies (HUFS), released their own line of Korean study materials, titled "Learn Korean with BTS” (Chang 2020). This program orients itself around Bora, an international ARMY, who is visiting Korea and aims to visit areas that are crucial to BTS identity. Through ARMYs' journey with Bora, they can learn phrases, vocabulary, and concepts in Korean that have significance not only to BTS, but also to the ARMY identity. While the company has attempted to capitalize on this interest in South Korea through BTS, the misfactoring of a top-down approach yet again signifies the importance of fandom. As many regarded following the course's release, the focus on fan experience and BTS-related content within the books was not enough, as the actual instructional material fell short, failing to provide enough quality information for the self-study usage it was intended. This led Bangtan Academy to step in, hosting courses utilizing the textbooks and offering explanations through Discord classes expanding upon the material for fans, for free (Bangtan Scholars ${ }^{7} \mathrm{BE}$ 2020). 


\section{ARMY as Soft Power and Affective Translation of Value}

In tandem with affinity and affective connection is the discussion of impact and how it translates into a form of soft power wielded by the fandom. Authors have often noted the impact Hallyu has had on influencing the global audience, as the popularity of Korean dramas and K-pop as a cultural product has resulted in more individuals across the globe seeking to learn Korean or visit Korea (Lee 2018; Oh 2018). However, the lack of recognition in terms of the work fandom plays in that appeal to foreign audiences leaves an evident gap in analysis. Soft power may be institutionally enacted through cultural diplomacy efforts and collaborations between governments and industry, but as Nye (2008) notes, diplomacy efforts do not always lead to soft power acquisition. Possessing the resources through, in this instance, BTS does not guarantee soft power; there is a key ingredient that is missing from the recipe. This is not to say BTS are not promoters of culture in their own right; rather, this is to say that the final step in the “co-opting" process Nye (2004) discusses is required. According to Lee (2009), this final stage falls on the part of strategy in mobilizing soft resources, but again, strategy does not always equate to achieving soft power (as cited in Kim and Jin 2016).

The missing link, here, is ultimately fandom.
ARMY, through their ability to raise awareness about BTS directly, offer the final and crucial piece in understanding how value can be translated into soft power. Connecting the world to BTS through acts of translation, videos, and other forms of content has had a direct impact on the success of the group, as well as their representation as beacons of South Korean popular culture. ARMY as a group are well aware of this potential and actively work towards it, understanding that the work they conduct has an impact in a multitude of capacities, but is also helping BTS reach the levels of success that they have, directly correlating and due in part to the global network of fan labour that exists. Particularly, it is the labour that directly links ARMY to BTS, ARMY to Korea, and Korea to the global stage. When reflecting on the impact they feel this type of work has had on both BTS and the fandom, several interviewees echoed these ideas, with one stating:

"Fan translators, including myself, have undeniably been contributing to BTS' success overseas. There are a handful of people who translate Korean originals into English, but there are dozens, if not hundreds, of people translating the English translations into their native languages."

Again, it is clear the impact this connected labour network has on maintaining connection between ARMY and BTS, but also in bringing BTS to a global stage. ARMY translate their affective connection to their group back to the 
community through their work, and work to bring the world's eyes to their artist. This is exemplified greatly within the realm of charity work taken on by fandom organizations such as One in An ARMY or Funds for Bangtan. While different in their content, their form parallels with ideas of raising awareness about BTS' own messages, whether it be music or philanthropy. One in An ARMY, the organizers behind many fundraising campaigns in BTS' name, such as the "\#MatchAMillion" 24 hour funding raising campaign in support of the Black Lives Matter movement (Cha 2020), focus their efforts in exemplifying the notion of ARMY being the face of BTS. Funds for Bangtan, along the same tangent, raise money in order to promote BTS' songs in the global charts, their efforts in mobilizing the fandom a large part the reason behind songs' success in the international sphere (Funds for Bangtan ${ }^{7}$ (USA/PR) n.d.). These are just two examples among the hundreds, if not thousands of collective ARMY efforts produced and enacted online that mobilize collective affect in the name of BTS. As one interviewee claimed, this sentiment is commonly held within the fan community, stating

"BTS has probably one of the most diverse international fandoms like $\cdots$ in age and culture... and I also feel like before that $\cdots$ there has never been a group that had so many fandom creators, like edit wise, like on YouTube there's so many videos of them like that are created by fans...
And like I really believe that international fandom is what made BTS so popular worldwide"

This recognition of ARMY's power is not only fandom exclusive, as media and government bodies have already realized the strength the fandom provides in promoting BTS, but also by osmosis, South Korea, to a global stage. Many public achievements for BTS also include nods to ARMY, as Lee (2019) notes, when President Moon Jae-in publicly congratulated BTS on their Billboard Hot 100 \#1, "he added his 'congratulations to ARMY for making their dreams come true"” (p. 6). ARMY represent the key piece of the puzzle towards soft power for South Korea through their affective labour efforts.

\section{Conclusion}

From this discussion, it is clear that while BTS are considered a powerful soft power resource, ARMY are the crucial factor in the equation. Firstly, as the data collected has highlighted, ARMY's fan labour acts as a means of recruiting new fans, whereby exposure and access is created in order to directly link potential audiences to BTS' story and cultural products. Whether it be through fan-created videos offering a more in depth look into the group's dynamics as one interviewee mentioned, 
or edited photos that circulate mainstream platforms, these cultural products constructed by fans work to bridge the gap between the passive listener and the avid fan. Fan creation and work acts as a key stepping stone in the process of becoming a fan and, ultimately, an ARMY.

Secondly, this links to a greater idea of global promotion that constitutes a large portion of the work undertaken by the fan community. The data presented showcases how fan labour operates at the level of promotion and distribution, specifically on an international scale, whereby transnational fans actively work to promote BTS on a global stage. Instances such as cupsleeve events, billboards, advertisements, and hashtags which originate in the fandom context inevitably extend into the mainstream. This work serves a dual purpose of celebrating BTS as artists, enriching the fan experience through public displays of affection, but also actively engages non-fan audiences through capturing interest. While this work could be and is positioned as a predecessor to the aforementioned finding of fan acquisition, it also works more broadly to globalize BTS as an artist. It simultaneously fosters connection between ARMY and BTS on a transnational level, and aids in the larger recognition of BTS in the global media sphere.

These two key findings finally elucidate how fan labour actively constructs an affinity for Korean culture within the larger framework of BTS audiences, producing a value that is not necessarily equatable with Marxist understandings of exchange value through labour. Rather, the value that is produced operates within the gift economy of fandom spaces, such as Twitter, Tumblr, or Facebook. This affective drive to contribute, to give back to both the community and BTS, results in promotion of the group within the visible, accessible mainstream sphere. Almost unintentionally, this value can be transformed into soft power through their position, first, as a crucial link in the chain of BTS as a soft resource.

As authors have mentioned, soft power is not always a guarantee. As Lee (2009) explains that Hallyu itself is not soft power, and the same can be understood for BTS' potential. BTS are artists, creatives who have, similarly to South Korea, risen above adversity and achieved success. Their story and talent has resulted in the large, transnational and transcultural fanbase they possess, but it is that fanbase and their collective efforts that led to this positionality of representations on the world stage. The members themselves acknowledge this repeatedly, with member Jimin having a signature hashtag after each award win: "\#우리아미상받았네” or “\#OurArmyWonAnAward”. ARMY labour is a significant component of BTS' success, but also represents a key facet in the larger project of South Korean soft power. While one could argue that ARMY themselves present a re-telling of soft power, dismantled from the state-level conception and reinterpreted through 
the lens of a digital public, this warrants further, though crucial, investigation. Instead, ARMY offer a case study of a dialectic of affect that procures their key position as leaders in the realm of nation branding. This form of appeal, turning the world's eyes to BTS and ultimately to South Korea, is not a top-down initiative, but rather a particular example of bottom-up, grassroots efforts premised on affect and group identification. It is easy to say that BTS themselves are a soft resource for the South Korean state, and they are, but what cannot be overlooked or denied is the power through which that has been achievable, sitting solely in the exchange economy and through the labour of the ARMY fan community.

〈Received December 12. 2020〉

〈Accepted January 28. 2021〉

\section{References}

AmyOt7. BTS favorite places in Korea. Reddit. Posted October 1, 2020. Reddit. https:// www.reddit.com/r/bangtan/comments/ j3isjx/bts_favorite__places_in_korea/

ARMY Language ${ }^{7}$ (2020), “\#LKwBTSTutoring ARMY ACADEMY will provide free tutoring sessions to help ARMYs with the Learn Korean with BTS lessons given by @ BigHitEnt. Read the poster below for all the details @BTS_twt @armyacademics,"
Twitter, [available at https://twitter.com/ army_language/status/1244434085625421 826].

“ARMY Map" (n.d.), How to use ARMYMAP, (accessed November 30, 2020), [available at https://www.armymap.net/Home_En]. Bangtan Academy ${ }^{7}$ (2020), "Happy Hangeul Day! The BANGTAN ACADEMY discord is officially open! We have 7 different ways to learn Korean and are now accepting students for our LKWBTS class! From classes to clubs to simple daily app check-ins, we offer a drama free learning environment for ARMY Purple heart 보라해!” Twitter, [available at https://twitter.com/Bangtan Academy_/status/1309536332104990721?s $=20]$.

Bangtan Scholars ${ }^{7} \mathrm{BE}$ (2020), "Want to learn Korean with other \#BTSARMY's? Our sister account 'BANGTAN ACADEMY' has officially open its discord! They have 7 different ways to learn $\&$ are now accepting students for their LKWBTS class! 다들 화 이팅하세요! 공부 열심히 해! More info: @BangtanAcademy_@BTS_twt," Twitter, [available at https://twitter.com/Bangtan Scholars/status/1309892026901692416? $\mathrm{s}=$ 20].

Baym, Nancy K. and Robert Burnett (2009), "Amateur experts," International Journal of Cultural Studies, 12(5), 433-49.

Bakioğlu, Burcu S (2016), "Exposing convergence: YouTube, fan labour, and anxiety of cultural 
production in Lonelygirl15," Convergence: The International Journal of Research into New Media Technologies, 24(2), 184-204. Big Hit Labels (2018), "BTS (방탄소년단) 'IDOL' Official MV”, YouTube, (accessed November 30, 2020), [available at https: $/ /$ www.youtube.com/watch? $\mathrm{v}=\mathrm{pBuZEG}$ YXA6E].

Burns, Axel (2006), "Towards Produsage: Futures for User-Led Content Production," in Proceeding of the 5th International Conference on Cultural Attitudes towards Technology and Communication, Australia, 275-84.

Cha, S. (2020), "BTS fans match group's $\$ 1$ million donation to Black Lives Matter," Reuters.

Chang, D. (2020), "(Yonhap Feature) Big Hit Edu aims to help global ARMY connect with BTS via Korean learning," Yonhap News Agency.

Connellan, S. (2017), "All anyone cared about at the AMAs was South Korean boy band BTS," Mashable.

Cummings, Milton C (2003), "Cultural diplomacy and the United States government: A survey." Washington, DC: Center for Arts and Culture.

De Kosnik, Abigail (2013), "Fandom as Free Labor," in Digital labor: The Internet as playground and factory, Trebor Scholz, ed. New York: Routledge, 187-212.

Dodson, P.C. (2020), “BTS Week on The
Tonight Show Starring Jimmy Fallon:

Watch Every Performance," Teen Vogue. Duffett, Mark, (2013), Understanding fandom: An introduction to the study of media fan culture. New York: Bloomsbury Academic. “Economic Effect of BTS' Conquest of Billboard Hot 100 Chart," (2020), KBS World Radio. Fuchs, Christian (2010), "Labor in Informational Capitalism and on the Internet," The Information Society, 26 (3), 179-96.

Funds for Bangtan ${ }^{7}$ (USA/PR) (n.d.), Twitter Page, [available at https://twitter.com/ fundsforbangtan].

Galuszka, Patryk (2014), "New Economy of Fandom," Popular Music and Society, 38 (1), 25-43.

Gill, Rosalind and Andy Pratt (2008), "In the Social Factory?: Immaterial Labour, Precariousness and Cultural Work," Theory, Culture \& Society, 25(7-8), 1-30.

Haddad, H. (2019), "BTS Named The Official Ambassadors Of Seoul For The Third Year In A Row," Eonline.

Han, Benjamin (2017), "K-Pop in Latin America: Transcultural Fandom and Digital Mediation," International Journal of Communication (19328036), 11, 2250-2269.

Hellekson, Karen (2009), “A Fannish Field of Value: Online Fan Gift Culture," Cinema Journal, 48(4), 113-118.

Helens-Hart, Rose (2014), "Promoting fan labor and "all things Web": A case study of Tosh.0," Transformative Works and 
Cultures, 15.

Herman, T. (2018a), "BTS Performs at KoreaFrance Friendship Concert in Paris with South Korean President in Attendance," Billboard.

Herman, T. (2018b), "BTS Awarded Order of Cultural Merit by South Korean Government," Billboard.

Hills, Matt (2002), Fan cultures. London: Routledge.

Jenkins, Henry (2006), Fans, bloggers, and gamers : Exploring participatory culture. New York: New York University Press. Jenkins, Henry (2008), Convergence Culture: Where Old and New Media Collide. New York: New York University Press.

Jenkins, Henry, Sam Ford, and Joshua Green (2018), Spreadable media: creating value and meaning in a networked culture. New York: New York University Press.

Jenkins, Henry (1992), Textual Poachers: Television fans \& participatory culture. New York: Routledge.

Jenson, Joli (1992), "Fandom as Pathology: The consequences of characterization," in The Adoring Audience: Fan culture and popular media, Lisa A. Lewis, ed. London: Routledge, 9-29.

Jin, Dal Yong (2016), New Korean wave transnational cultural power in the age of social media. Urbana, IL: University of Illinois Press.

Jin, Dal Yong and Kyong Yoon (2014), “The social mediascape of transnational Korean pop culture: Hallyu 2.0 as spreadable media practice," New Media \& Society, 18(7), 1277-92.

Kang, M. (2020). "BTS Receives James A. Van Fleet Award And Delivers Speech," Soompi.

Kim, Soojin (2017), "Controlling or Supporting?: A History of Cultural Policies on Popular Music," in Made in Korea: Studies in Popular Music, Hyunjoon Shin and SeungAh Lee, eds. New York, NY: Routledge, 169-180.

Kim, Tae Young and Dal Yong Jin (2016), "Cultural Policy in the Korean Wave: An Analysis of Cultural Diplomacy Embedded in Presidential Speeches," International Journal of Communication (19328036), 10, 5514-34.

Kim, Andrew Eungi, Fitria Mayasari, and Ingyu Oh (2013), "When Tourist Audiences Encounter Each Other: Diverging Learning Behaviors of K-pop Fans from Japan and Indonesia," Korea Journal, 53(4), 59-82.

Kozymka, Irena (2014), The diplomacy of culture: The role of UNESCO in sustaining cultural diversity. New York, NY: Palgrave. Lamerichs, Nicolle (2018), Productive Fandom: Intermediality and Affective Reception in Fan Cultures. Amsterdam: Amsterdam University Press.

Lee, Jamie Shinhee (2018), "The Korean Wave, K-Pop Fandom, and Multilingual 
Microblogging," in Multilingual Youth Practices in Computer Mediated Communication, Unn Røyneland and Cecelia Cutler, eds. Cambridge: Cambridge University Press, 205-223.

Lee, Jeeheng (2019), BTS and ARMY Culture.

Seoul: CommunicationBooks.

Lee, Geun (2009), "A soft power approach to the 'Korean Wave'," The Review of Korean Studies, 12(2), 123- 137.

Lipshutz, J. (2017), "BTS Thanks Fans For

Top Social Artist Win at Billboard Music Awards 2017: Watch," Billboard.

Melissen, Jan and Mai'a K. Davis Cross (2013), "Introduction," in European public diplomacy: Soft power at work, Jan Melissen and Mai'a K. Davis Cross, eds. New York, NY: Palgrave Macmillan, xvii-xix.

Milner, R.M. (2009), "Working for the text: Fan labor and the New Organization," International Journal of Cultural Studies, 12(5), 491-508.

Moisander, Johanna, Saara Könkkölä, and PikkaMaaria Laine (2013), "Consumer workers as immaterial labour in the converging media markets: three value-creation practices," International Journal of Consumer Studies, 37(2), 222-27.

Morimoto, Lori and Bertha Chin (2017), "Reimagining the Imagined Community: Online Media Fandoms in the Age of Global Convergence," in Fandom, Second Edition: Identities and Communities in a
Mediated World, Jonathan Gray, Cornel Sandvoss and C. Lee Harrington, eds. New York: NYU Press, 174-188.

Nye, Joseph (2004), Soft power: The means to success in world politics. New York: Public Affairs.

Nye, Joseph (2008), "Public Diplomacy and Soft Power," The Annals of the American Academy of Political and Social Science, 616(1), 94-109.

Nye, Joseph, and Youna Kim (2013), "Soft power and the Korean Wave," in The Korean Wave: Korean Media Go Global, Youna Kim, ed. Abingdon, UK: Routledge, 31-42.

Oberc, Agnieszka (2016), “I Write. You Write. They Write. The Literary Works of Fandom as a Factor in Integrating the Community," in On-line/Off-line: Between Text and Experience: Writing as a Lifestyle, Jaroskawa Płuciennika and Peter Gärdenfors, eds. Jagiellonian University Press, 63-74.

Oh, Ingyu and Hyo-Jung Lee (2014), “K-pop in Korea: How the Pop Music Industry Is Changing a Post-Developmental Society," Cross-Currents: East Asian History and Culture Review, 3(3), 72-93.

Oh, Ingyu and Hyo-Jung Lee (2013), "Mass Media Technologies and Popular Music Genres: K-pop and YouTube," Korea Journal, 53(4), 34-58.

Oh, Youjeong (2018), Pop City: Korean Popular Culture and the Selling of Place, Cornell 
University Press.

Jonathan Gray, Cornel Sandvoss and C. Lee Harrington

Sandvoss, Cornel, Jonathan Gray and C. Lee Harrington (2017), "Introduction: Why Still Study Fans?" in Fandom, Second Edition: Identities and Communities in a Mediated World, Jonathan Gray, Cornel Sandvoss and C. Lee Harrington, eds. New York: NYU Press, 1-26).

Shetty, K. (2020), “BTS Week on Fallon: Septet lights up Gyeongbokgung Palace in black hanboks to give thrilling Idol performance," Pinkvilla.

Stanfill, Mel (2019), Exploiting Fandom: How the Media Industry Seeks to Manipulate Fans. Iowa City: University of Iowa Press. Sung, Sang-Yeon (2014), “K-pop Reception and Participatory Fan Culture in Austria," Cross-Currents: East Asian History and Culture Review, 3(3), 56-71.

Terranova, Tiziana (2013), "Free Labor: Producing
Culture for the Digital Economy," in Digital labor: The Internet as playground and factory, Trebor Scholz, ed. New York: Routledge, 33-57.

Thornton, Sarah (1995), Club cultures music, media and subcultural capital. Cambridge: Polity Press.

Turk, Tisha (2013), "Fan work: Labor, worth, and participation in fandoms gift economy," Transformative Works and Cultures, 15.

Walsh, John (2014), "Hallyu as a Government Construct: The Korean Wave in the Context of Economic and Social Development," in The Korean Wave: Korean Popular Culture in Global Context, Yasue Kuwahara, ed. Palgrave Macmillan: New York, 13-31.

Watson, Iain (2012), “South Koreas State-led Soft Power Strategies: Limits on InterKorean Relations," Asian Journal of Political Science, 20(3), 304-25.

Willis, Paul E. (2014), Profane culture. Princeton: Princeton University Press. 